\title{
Recombinant laminin $\alpha 5$ LG1-3 domains support the stemness of human mesenchymal stem cells
}

\author{
SUJIN LEE ${ }^{1 *}$, DONG-SUNG LEE ${ }^{2 *}$ and JUN-HYEOG JANG ${ }^{1}$ \\ ${ }^{1}$ Department of Biochemistry, College of Medicine, Inha University, Incheon 22212; \\ ${ }^{2}$ College of Pharmacy, Chosun University, Gwangju 61452, Republic of Korea
}

Received April 23, 2020; Accepted November 24, 2020

DOI: $10.3892 /$ etm.2020.9597

\begin{abstract}
The extracellular matrix components laminin and elastin serve key roles in stem cell therapy. Elastin-like polypeptides (ELPs), derived from a soluble form of elastin, affect the proliferation and differentiation of various types of cells. In the present study, a novel protein was designed containing globular domains 1-3 of laminin $\alpha 5$ (L $\alpha 5$ LG1-3) fused to ELPs (La5LG1-3/ELP). La5LG1-3/ELP was expressed in Escherichia coli and displayed a molecular size of $\sim 70 \mathrm{kDa}$ on $12 \%$ SDS-polyacrylamide gels. The cellular activities, such as cellular adhesion (adhesion assay) and proliferation (MTT cytotoxicity assay), of human mesenchymal stem cells (hMSCs) treated with $1 \mu \mathrm{g} / \mathrm{ml}$ of L $\alpha 5 \mathrm{LG} 1-3 /$ ELP were enhanced compared with those of untreated cells. Additionally, the number of undifferentiated hMSCs and their degree of stemness were assessed based on the gene expression levels of the stem cell markers cluster differentiation 90 (CD90), endoglin (CD105) and CD73. The expression levels of these markers were upregulated by 2.42-, 2.29- and 1.92-fold, respectively, in the hMSCs treated with La5LG1-3/ELP compared with the levels in untreated controls. Thus, La5LG1-3/ELP may be used to enhance the viability of hMSCs and preserve their undifferentiated state, whereby the clinical applications of hMSCs may be improved.
\end{abstract}

\section{Introduction}

One of the key treatments in regenerative medicine is stem cell therapy. Thus, the maintenance of stem cells is essential. Maintenance of the undifferentiated state and proliferation activity of stem cells is essential to sustain their functionality (1). It has been hypothesized that this requirement can

Correspondence to: Professor Jun-Hyeog Jang, Department of Biochemistry, College of Medicine, Inha University, 100 Inha, Michuhol, Incheon 22212, Republic of Korea

E-mail: juhjang@inha.ac.kr

*Contributed equally

Key words: laminin, elastin, elastin-like polypeptide, cell adhesion, cell proliferation, mesenchymal stem cells, stemness, stem cell therapy be met by mimicking the in vivo extracellular matrix (ECM) configuration, thereby modulating the activity of stem cells in vitro (2). The principle behind this hypothesis is that the ECM not only functions as structural support for stem cells in vivo but also provides biochemical cues for their maintenance versus directed differentiation (3).

Basement membranes (BMs) are a subgroup of the ECM that is necessary for cell differentiation during early developmental processes. In addition, BMs are critical for the formation and maintenance of mature tissues $(4,5)$. Laminin, one of the components of BMs, consists of three genetically distinct subunits called $\alpha, \beta$ and $\gamma$ chains, which are assembled into cross-shaped molecules $(6,7)$. At present, $5 \alpha, 3 \beta$ and $3 \gamma$ chains, as well as at least 16 different trimeric laminin isoforms are known in humans and mice each (8). Laminin-mediated cell attachment and cellular behavior are achieved by five different $\alpha$ chains. Among them, laminin $\alpha 5$ (L $\alpha 5$ ) plays a key role during embryogenesis. L $\alpha 5$, expressed in the inner cell mass of the blastocyst, supports the self-renewal of embryonic stem cells $(7,9)$. L $\alpha 5$-knockout mouse or zebrafish models have severe developmental defects, demonstrating the effect of L $\alpha 5$ on stem cell maintenance and embryonic development (10). Most of the cellular binding regions of laminins are primarily located in the C-terminal large globular (G) domain of the protein. The $\mathrm{G}$ domain consists of only the laminin $\alpha$ chain and is subdivided into five homologous LG domains $(4,11)$. LG domains are important for interaction with cells (12). LG1, LG2 and LG3 are the first three of the LG domains, assembled into a clover-leaf arrangement to form the putative binding sites of laminin-binding integrin (11). LG1-3 domains of the $\alpha 5$ chain comprise cell-binding sites, which is mediated by integrins $\alpha 3 \beta 1, \alpha 6 \beta 1$ and $\alpha 6 \beta 4$. LG4 domain of the $\alpha 5$ chain binds to $\alpha$-dystroglycan and heparin (12-14).

Elastin is an important ECM protein found abundantly in blood vessels and serves as a biomechanical and physiological signal for cells (15). The soluble form of elastin, tropoelastin, is primarily located in elastic tissues. It has been reported to promote the proliferation of hematopoietic stem cells (HSCs) and mesenchymal stem cells (MSCs) (16). Additionally, it is often used in the form of cross-linked gel fibers or injectable scaffolds for tissue engineering and drug delivery (17). Elastin-like polypeptides (ELPs) are recombinant peptide polymers composed of VPGXG pentapeptides (found in tropoelastin), where $\mathrm{X}$ stands for any amino acid residue except 
proline (18). ELPs exhibit biocompatibility that is similar to elastin in terms of mechanical and viscoelastic properties. ELPs effectively modulate the migration, proliferation, and differentiation of various type of mammalian cells (19). These polypeptides can be genetically engineered to modulate their structural and biological properties and exhibit an inverse phase transition behavior in response to the changes in their solutions (20). Recombinant ELPs have been expressed in E. coli and subsequently purified through a separation process known as inverse transition cycling (ITC) (21).

Human MSCs (hMSCs) are pluripotent stem cells that can differentiate both in vitro and in vivo. In particular, it is known that hMSCs can differentiate into the mesenchymal lineage, forming bone, cartilage, adipose, and muscle cells. These stem cells can be isolated from cord blood, placental fluids, and multiple adult tissues, such as bone marrow, adipose tissue, skeletal muscle, and connective tissue (22-27). Previously, we have shown that a recombinant human laminin $\alpha 2$ LG1-3 promotes hMSCs physiology in vitro, including cell adhesion, proliferation, and stemness (28). In this study, we fused the coding sequence of ELP to laminina5 LG1-3 domains and examined the cellular effects of this fusion construct (La5LG1-3/ELP) on hMSCs.

\section{Materials and methods}

Construction and purification of La5LG1-3/ELP fusion protein. La5LG1-3 coding sequence containing integrin-binding modules LG1-LG3 of laminin $\alpha 5$ (La5) and ELP coding sequence were synthesized (Genotech).

Based on the characteristics of ELP guest residues (19-21), ELP coding sequence was designed by inserting Val,Leu, and Gly (ratio of 17:4:9) into ELP guest residue position. The full-length ELP(V17L4G9-30) coding sequence containing Val, Leu, and Gly in the fourth guest residue (Xaa) (Val-Pro-Gly-Xaa-Gly) of the pentapeptide repeat is VPGGG VPGVG VPGGG VPGVG VPGVG VPGGG VPGVG VPGVG VPGGG VPGLG VPGVG VPGVG VPGGG VPGVG VPGLG VPGVG VPGVG VPGGG VPGVG VPGLG VPGVG VPGVG VPGGG VPGVG VPGLG VPGVG VPGVG VPGGG VPGVG VPGGG.

The La5LG1-3 construct was double digested with SacI and KpnI and then cloned into the expression vector pBAD-His (Invitrogen; Thermo Fisher Scientific, Inc.) to construct the pBAD-His-La5LG1-3. Next, ELP construct was double digested with $K p n \mathrm{I}$ and EcoRI and then cloned into pBAD-His-La5LG1-3 to construct the pBAD-His-L $\alpha 5$ LG1-3/ELP.

The recombinant pBAD-His-L $\alpha 5$ LG1-3/ELP was transformed into $E$. coli TOP10 cells through heat shock at $42^{\circ} \mathrm{C}$. A single colony was selected and inoculated into $20 \mathrm{ml}$ Luria-Bertani (LB) media (LPS Solution) containing $100 \mu \mathrm{g} / \mathrm{ml}$ ampicillin (LB-Amp) overnight at $37^{\circ} \mathrm{C}$. This overnight culture was then mixed with 1 liter LB medium and incubated until the $\mathrm{OD}_{600}$ reached 0.4. Subsequently, L-Arabinose was added to a final concentration of $0.1 \%(\mathrm{w} / \mathrm{v})$, and the culture temperature was decreased to $20^{\circ} \mathrm{C}$. After $6 \mathrm{~h}$ of induction, bacterial cells were pelleted by centrifugation at $4^{\circ} \mathrm{C}$ and $6000 \mathrm{x}$ for $15 \mathrm{~min}$. The pellet was resuspended in sodium chloride-Tris-EDTA buffer and then lysed by sonication. The lysate was obtained by centrifugation at $13,000 \mathrm{x} \mathrm{g}$ and $4^{\circ} \mathrm{C}$ for $20 \mathrm{~min}$. To obtain La5LG1-3/ELP, the supernatant was purified through ITC.
Briefly, the supernatant was transferred into fresh tube with $3 \mathrm{M}$ $\mathrm{NaCl}$ pre-heated to $40^{\circ} \mathrm{C}$, followed by centrifugation at $40^{\circ} \mathrm{C}$ to obtain the L $\alpha 5 \mathrm{LG} 1-3 / \mathrm{ELP}$ pellet. After discard of supernatant containing soluble La5LG1-3/ELP, and the pellet was re-solubilized in cold phosphate-buffered saline. The resulting solution was centrifuged at $4^{\circ} \mathrm{C}$ to remove any insoluble protein, and the supernatant, containing pure La5LG1-3/ELP, was kept. The purity of this solution was analyzed through $12 \%$ SDS-PAGE, followed by Coomassie blue staining. Additionally, western blots analysis was performed using a peroxidase-conjugated monoclonal anti-polyhistidine antibody (His antibody, sc-8036 HRP; Santa Cruz Biotechnology, Inc.) diluted at 1:1,000 to assess the expression of La5LG1-3/ELP. The size of the immunodetected protein was determined based on the pre-stained protein markers (Elpis Biotech) electrophoresed in parallel lanes.

Cell culture. Primary hMSCs were kindly provided by Dr Sung-Won Kim (St. Mary's Hospital, the Catholic University of Korea) (29,30). The cells were maintained in a humidified incubator at $37{ }^{\circ} \mathrm{C}$ with $5 \% \mathrm{CO}_{2}$ and cultured in the growth medium (minimum essential medium, $\alpha$-modification) ( $\alpha$-MEM) (Welgene) containing 10\% fetal bovine serum (Welgene), $100 \mu \mathrm{g} / \mathrm{ml}$ streptomycin, $100 \mathrm{U} / \mathrm{ml}$ penicillin, and $0.25 \mu \mathrm{g} / \mathrm{ml}$ amphotericin B (Invitrogen; Thermo Fisher Scientific, Inc.). Confluent cells were passaged by trypsinization ( $0.25 \%$ trypsin-EDTA solution for $3 \mathrm{~min})$. Cells were maintained for three passages before use for further cell experiments.

Adhesion assay. Cell adhesion assay was carried out using crystal violet. Culture plates were coated with $0,0.01,0.05$, $0.1,0.5,1.0$, or $5.0 \mu \mathrm{g} / \mathrm{ml}$ of purified L $\alpha 5 \mathrm{LG} 1-3 / \mathrm{ELP}$ protein for $2 \mathrm{~h}$ at $37^{\circ} \mathrm{C}$. Following three rinse with Dulbecco's phosphate-buffered saline (DPBS) (Welgene), the plates were blocked with $0.5 \%(\mathrm{w} / \mathrm{v})$ bovine serum albumin (BSA) (Gibco; Thermo Fisher Scientific, Inc.) in DPBS for $1 \mathrm{~h}$ at $37^{\circ} \mathrm{C}$. Subsequently, hMSCs were added $\left(5 \times 10^{4}\right.$ cells/well $)$ and incubated at $37^{\circ} \mathrm{C}$ for $30 \mathrm{~min}$. Three replicates were performed for each treatment. After incubation, non-attached cells were removed by three rinses with DPBS, and the remaining cells were fixed by incubation in $3.7 \%$ formalin solution for $20 \mathrm{~min}$ at room temperature. The fixed cells were stained with $0.25 \%$ (w/v) crystal violet (Sigma-Aldrich; Merck KGaA) for $30 \mathrm{~min}$ at room temperature. Subsequently, they were extensively rinsed with DPBS and then lysed using 2\% SDS. The culture plates were read on a microplate reader (BioTek) at $570 \mathrm{~nm}$. Additionally, cell adhesion was monitored with 15 min intervals to confirm the adhesion over time. Cell adhesion activity was normalized relative to uncoated plates.

MTT cytotoxicity assay. Twenty-four-well plates were coated with $1 \mu \mathrm{g} / \mathrm{ml} \mathrm{L} \alpha 5 \mathrm{LG} 1-3 / \mathrm{ELP}$ protein for $2 \mathrm{~h}$ at $37^{\circ} \mathrm{C}$ and then rinsed three times with DPBS. Subsequently, hMSCs were added $\left(1 \times 10^{4}\right.$ cells/well) and incubated for 7 days at $37^{\circ} \mathrm{C}$. Three replicates were performed, and cell proliferation was assessed by the 3-(4,5-dimethylthiazol-2-yl)-2,5-diphenyltetrazolium bromide (MTT; AMRESCO Inc.) assay, which measures the metabolic activity of viable cells, according to the manufacturer's directions (Promega). Briefly, cells were rinsed three times with DPBS and then incubated with $0.5 \mathrm{ml} /$ well of 
Table I. Sequences of the primers used for reverse transcription-quantitative PCR.

\begin{tabular}{lll}
\hline Gene & Forward primer & \multicolumn{1}{c}{ Reverse primer } \\
\hline$\beta$-actin & 5'-TGGCACCCAGCACAATGAAGAT-3' & 5'-TACTCCTGCTTGCTGATCCA-3' \\
CD90 & 5'-CCAAAGGCTTCTTCTTGCTG-3' & 5'-CCACCAAATGTGAAGACGTG-3' \\
CD105 & 5'-GAAAATGGAGCTCCTGGTCA-3' & 5'-ACCCTTAGCACCAACAGCAC-3' \\
CD73 & 5'-CAGTACCAGGGCACTATCTGG-3' & 5'-AGTGGCCCCTTTGCTTTAAT-3'
\end{tabular}

$\mathrm{CD}$, cluster of differentiation.

A

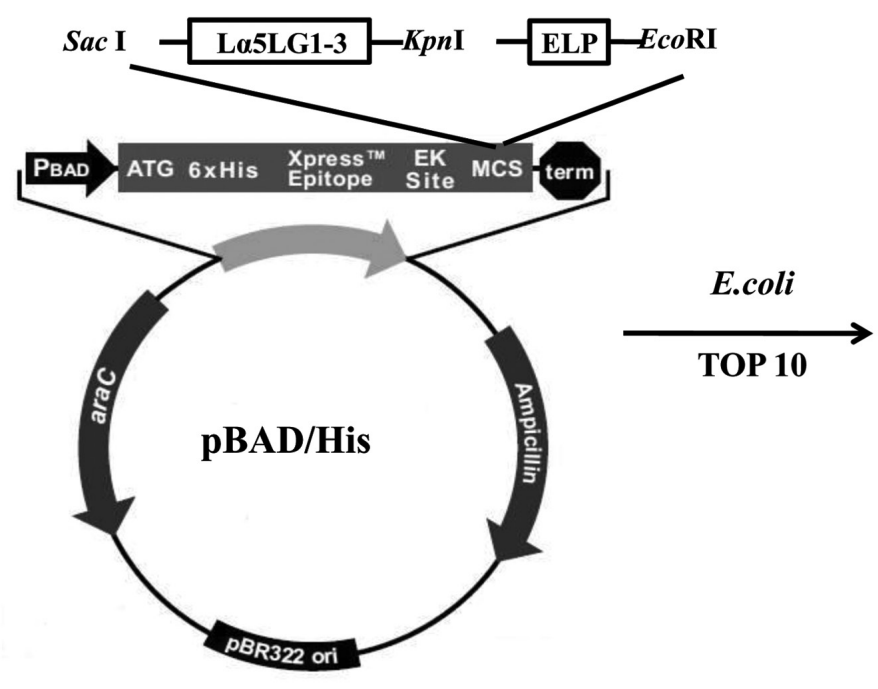

B kDa

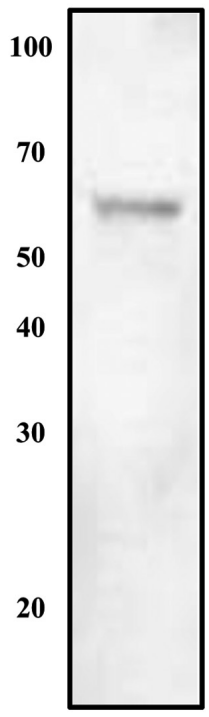

Figure 1. Cloning and purification of recombinant La5LG1-3/ELP. (A) cDNA encoding ELP was cloned into the pBAD-HisA-L $\alpha 5$ LG1-3 expression vector. (B) Molecular weight of the protein was estimated as $70 \mathrm{kDa}$ via western blotting probed using an anti-His6-tag monoclonal antibody. L $25 \mathrm{LG1-3/ELP,} \mathrm{globular}$ domains 1-3 of laminin $\alpha 5 /$ elastin-like polypeptide.

$5 \mu \mathrm{g} / \mathrm{ml}$ MTT in DPBS for $2 \mathrm{~h}$ at $37^{\circ} \mathrm{C}$. Afterward, the MTT solution was removed, and the resulting formazan crystals were dissolved in $150 \mu \mathrm{l} /$ well of dimethyl sulfoxide. The plates were read at $570 \mathrm{~nm}$ on a microplate reader (BioTek). Data were normalized using the uncoated control.

Quantitative reverse transcription-polymerase chain reaction ( $q R T-P C R)$. The total RNA of the cell was isolated using the Easy-Spin Total RNA Extraction Kit and then purified following the manufacturer's directions (Intron). The RNA amount and quality were assessed using a NanoDrop 2000 spectrophotometer (Thermo Fisher Scientific, Inc.). Next, cDNA was synthesized from $1 \mu \mathrm{g}$ of total RNA by using the High Capacity cDNA Reverse Transcription Kit according to the manufacturer's directions (Applied Biosystems; Thermo Fishier Scientific, Inc.). qRT-PCR was performed using SYBR-Green PCR Master Mix (Toyobo) and the ABI Step One Real-Time PCR System (Applied Biosystems; Thermo Fisher Scientific, Inc.). The PCR conditions were as follows: $10 \mathrm{~min}$ at $95^{\circ} \mathrm{C}$ and 40 cycles of $95^{\circ} \mathrm{C}$ for $15 \mathrm{sec}$ and $60^{\circ} \mathrm{C}$ for $1 \mathrm{~min}$. The gene expression level was normalized to that of $\beta$-actin and estimated with the comparative $C_{q}$ method (31). Each experiment per sample was performed in triplicate. The primers used are listed in Table I.
Statistical analysis. ANOVA followed by a post-hoc Tukey's test was used for comparisons between various groups. Differences between two groups were tested via unpaired Student's t-test: P-value $<0.05$ was considered significant $\left({ }^{*} \mathrm{P}<0.05,{ }^{* *} \mathrm{P}<0.01\right.$ and $\left.{ }^{* * *} \mathrm{P}<0.001\right)$. Experiments were repeated three times, and the results are presented as mean $\pm \mathrm{SD}$.

\section{Results}

Expression and purification of L $\alpha 5 L G 1-3 / E L P$ protein. To make the recombinant La5LG1-3/ELP construct, the La5LG1-3 sequence was inserted into the pPAD-HisA expression vector. Then, the ELP sequence was inserted into the resulting pBAD-His-L $\alpha 5 \mathrm{LG} 1-3$ expression vector. The L $\alpha 5$ LG1-3/ELP fusion protein retained the phase transition property of ELP. Thus, L $\alpha 5$ LG1-3/ELP could be purified through ITC. The molecular size of L $\alpha 5$ LG1-3/ELP was estimated at approximately $70 \mathrm{kDa}$ on $12 \%$ SDS-polyacrylamide gels stained with Coomassie blue. The expression of L $\alpha 5$ LG1-3/ELP was verified by western blotting with a peroxidase-conjugated monoclonal anti-polyhistidine antibody specific to the N-terminal His-tag (Fig. 1). Production of this La5LG1-3/ELP protein was well-established and used in subsequent experiments. 


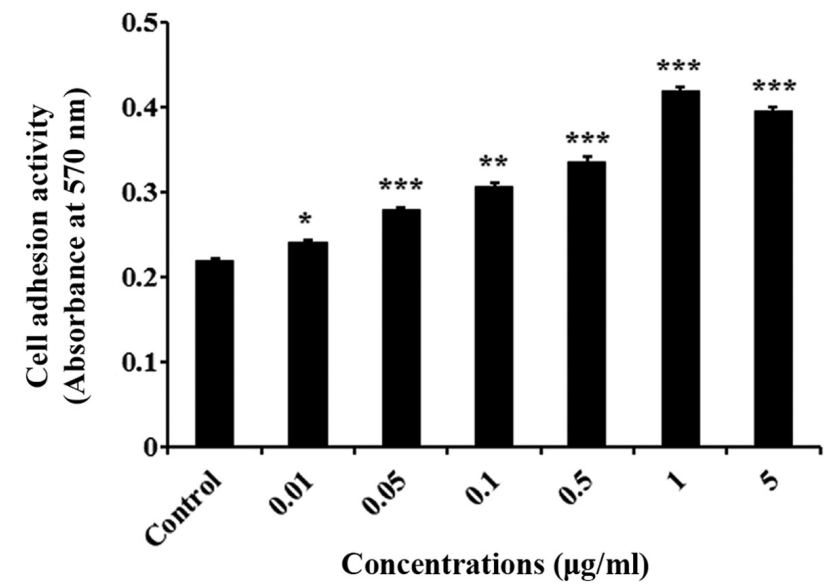

Figure 2. Adhesion of human mesenchymal stem cells in plates coated with recombinant La5LG1-3/ELP. Attached cells were observed using the crystal violet assay, and the results are expressed as the mean $\pm \mathrm{SD}$ of three independent experiments. ${ }^{*} \mathrm{P}<0.05,{ }^{* *} \mathrm{P}<0.01$ and ${ }^{* * *} \mathrm{P}<0.001$ vs. control. L $\alpha 5$ LG1-3/ELP, globular domains 1-3 of laminin $\alpha 5 /$ elastin-like polypeptide.

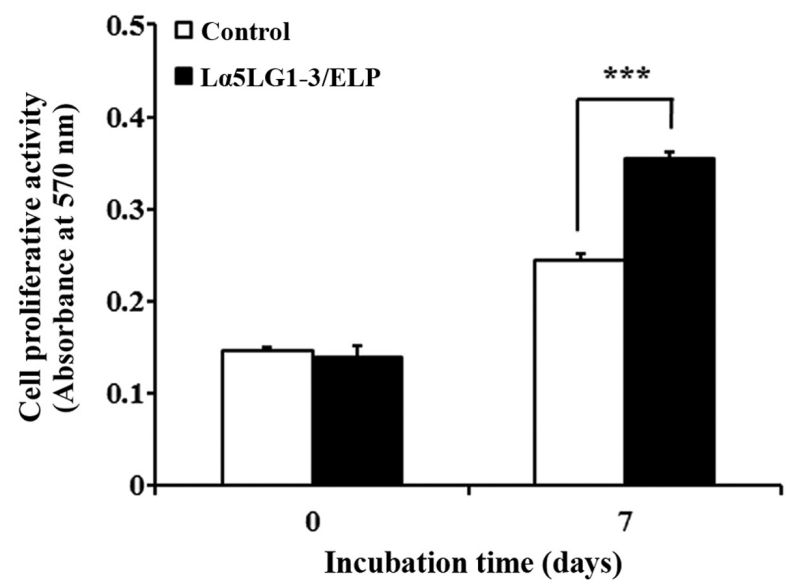

Figure 3. Effect of recombinant La5LG1-3/ELP on the proliferation of human mesenchymal stem cells evaluated using MTT assay. The results are expressed as the mean $\pm \mathrm{SD}$ of three independent experiments. ${ }^{* * *} \mathrm{P}<0.001$. La5LG1-3/ELP, globular domains 1-3 of laminin $\alpha 5 /$ elastin-like polypeptide.

La5LG1-3/ELP promotes the adhesion of hMSCs. Cell adhesion assay was carried out using crystal violet to determine the effect of La5LG1-3/ELP on the adhesion of hMSCs. As shown in Fig. 2 $(\mathrm{P}<0.001)$, the attachment of hMSCs was significantly better in the wells coated with L $\alpha 5$ LG1-3/ELP than in the uncoated, control wells. Moreover, La5LG1-3/ELP improved the cell adhesion in a dose-dependent manner, with the cell adhesion saturated at $1 \mu \mathrm{g} / \mathrm{ml}$ of La5LG1-3/ELP. Therefore, La5LG1-3/ELP was used at $1 \mu \mathrm{g} / \mathrm{ml}$ in the subsequent experiments.

La5LG1-3/ELP enhances the proliferation of hMSCs. We measured the effect of La5LG1-3/ELP on the proliferative activity of hMSCs by using the MTT assay. Toward this end, 24-well plates were coated with La5LG1-3/ELP, and hMSCs were incubated in these coated wells for 7 days. Additionally, experiments were conducted in two groups of 0 and 7 days for comparison. After 7 days, the proliferation of hMSCs increased 1.45 -fold $(\mathrm{P}<0.001$; Fig. 3) in the coated well compared with the proliferation in the

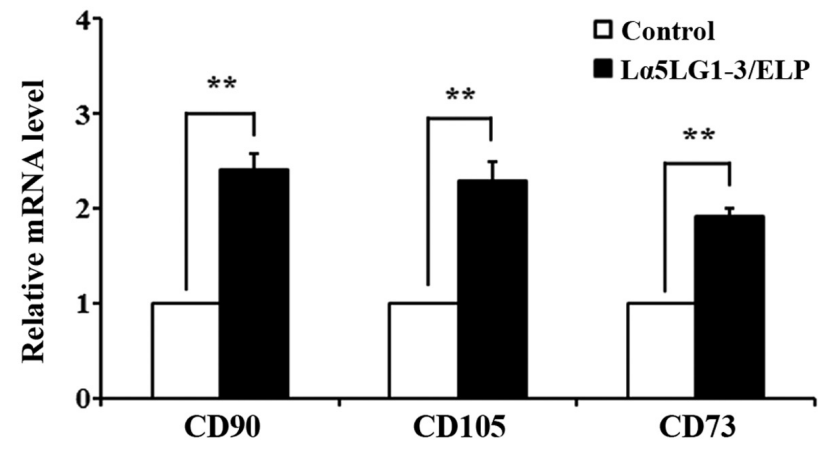

Figure 4. Recombinant La5LG1-3/ELP enhances the stemness of human mesenchymal stem cells. The mRNA expression levels of CD90, CD105 and CD73 were measured using reverse transcription-quantitative PCR. The mRNA expression levels of each gene were normalized relative to the mRNA levels of $\beta$-actin, which served as an internal control. The results are expressed as the mean $\pm \mathrm{SD}$ of three independent experiments. ${ }^{* *} \mathrm{P}<0.01$. L $\alpha 5$ LG1-3/ELP, globular domains 1-3 of laminin $\alpha 5 /$ elastin-like polypeptide; $\mathrm{CD}$, cluster of differentiation.

controls (uncoated wells). This result demonstrated that La5LG1-3/ELP enhances the proliferation of hMSCs.

La5LG1-3/ELP helps maintain the stemness of hMSCs. qRT-PCR was performed to confirm that L $\alpha 5$ LG1-3/ELP maintains stemness of hMSCs at the gene expression level. The distinctive stem cell surface marker genes cluster differentiation 90 (CD90), endoglin $(C D 105)$ and $C D 73$ were chosen. The mRNA levels of these markers in hMSCs grown with or without La5LG1-3/ELP for 7 days are presented in Fig. 4. The gene expression levels of $C D 90, C D 105$ and $C D 73$ were upregulated in the presence of La5LG1-3/ELP compared with the levels in the uncoated control wells.

\section{Discussion}

Cells must interact with the ECM because it supports many cellular activities, including adhesion, proliferation, and differentiation (32). Laminin and elastin are two ECM proteins predominantly present in the BMs of most tissues in humans (33). The major multifunctional components of the ECM include the followings: i) Laminin is one of the glycoproteins and a major factor affecting cell attachment, proliferation, differentiation and survival. The five globular domains of the $\alpha$-chain, LG domains, are known to have a critical effect on cells by binding to integrins. ii) Elastin affects the biomechanical and physiological properties of cells $(32,33)$. In this work, we engineered a novel fusion protein composed of LG1-3 domains laminin $\alpha 5$ chain and ELPs, recombinant forms of elastin.

The L $\alpha 5$ LG1-3/ELP fusion protein was purified through ITC, based on the inverse phase transition properties of ELP. As shown in Fig. 1, the total molecular weight of the recombinant protein was estimated at approximately $70 \mathrm{kDa}$ by performing western blot analysis with and antibody that detects the amino-terminal His-tag. The production of the recombinant protein was successful, and the presence of La5LG1-3/ELP was determined by protein identification. The major BM proteins laminins, exert biological activities, such as promoting cell attachment, differentiation, and migration, as well as angiogenesis and formation of neurite outgrowths $(5,6)$. 
Integrins are the most characteristic laminin receptors that the diverse biological activities of laminins. Moreover, interactions of cells with laminins are crucial to cellular adhesion $(4,33)$.

The hMSCs are pluripotent stem cells that can differentiate into mesenchymal lineages $(22,23)$. To assess the effect of La5LG1-3/ELP on the adhesion of hMSCs, we performed the cell adhesion assay by using crystal violet. La5LG1-3/ELP enhanced the adhesion of hMSCs in a dose-dependent manner, with saturation at $1 \mu \mathrm{g} / \mathrm{ml}$. Therefore, La5LG1-3/ELP, was used at the concentration of $1 \mu \mathrm{g} / \mathrm{ml}$ for the subsequent experiments (Fig. 2). To further estimate the effect of La5LG1-3/ELP on hMSC proliferation, MTT assay was carried out. For this purpose, hMSCs were grown in La5LG1-3/ELP coated 24-well plates for 7 days and then used for the assay. In addition, for comparison, experiments were conducted in two groups, 0 day and 7 day. As shown in Fig. 3, after 7 days, the cell proliferation was 1.45 -fold higher in the coated plates than in the uncoated controls. Taken together, these results suggest that L $\alpha 5$ LG1-3/ELP improves the proliferation of hMSCs.

It has been reported that hMSCs express CD44, CD71, CD73, CD90 (Thy-1), CD105 (endoglin), and CD271, but not the co-stimulatory molecules CD80, CD86 and CD40, or the hematopoietic markers CD14, CD34 and CD45 (22). In addition, hMSCs express various surface receptors, such as integrin, that bind to the LG1-3 domain of the laminin $\alpha$-chain. Therefore, hMSCs are anticipated to bind to recombinant laminin $\alpha 5$ LG1-3 (La5LG1-3) (27). To investigate the effect of La5LG1-3/ELP on the maintenance of the stemness properties of hMSCs, the gene expression levels of the stem cell surface markers CD73, CD90 and CD105 were measured through qRT-PCR. Total RNA was isolated from cells cultured in La5LG1-3/ELP coated plates for 7 days, cDNA was synthesized and surface markers were examined, and CD90, CD105, and CD73 were stem cell surface markers that are expressed by hMSCs at varying levels (34). CD90 is a stem cell surface-anchoring glycoprotein that plays a key role in cell motility, and is essential for stem cell growth and differentiation $(35,36)$. CD90 expression at high levels is associated with the undifferentiated state of MSCs (37). CD105, also called $\mathrm{SH} 2$, is a component of a receptor complex that transforming growth factor- $\beta$ (TGF- $\beta$ ), which modulates stem cell migration, proliferation, and differentiation. Additionally, CD105 is also used for purifying hMSCs through an immunoisolation method. CD105-positive MSCs can differentiate into chondrogenic, osteogenic, and adipogenic lineages $(36,38,39)$. CD73, also termed as ecto-5'-nucleotidase, is a glycosyl phosphatidylinositol-linked membrane protein found on the surface of multiple cell types. It is found on the surfaces of hematopoietic and mesenchymal stem cells and functions in numerous physiological processes in various tissues (40-42). In addition, CD73 is known to modulates epithelial-mesenchymal stem cell transition and stemness in ovarian cancer initiating cells (43). As shown in Fig. 4, the expression levels of the surface markers CD90, CD105 and CD73 were 2.42-, 2.29- and 1.92-fold higher, respectively, than the levels in the control. These results indicate that L $\alpha 5$ LG1-3/ELP contributes to maintaining the undifferentiated state of hMSCs. The increase in CD90, CD105 and CD73 levels in hMSCs cultured in L $\alpha 5$ LG1-3/ELP-coated plates suggest that L $\alpha 5$ LG1-3/ELP supports the stemness properties of hMSCs. In order to further clarify the effect of La5LG1-3/ELP, and experiment at the protein level such as western blot will be performed later.

In conclusion, La5LG1-3/ELP maintains the undifferentiated state of hMSCs and promotes their adhesion, proliferation, and stemness. Therefore, La5LG1-3/ELP can potentially be used during MSC therapy to enhance the viability of these stem cells and their maintenance at the undifferentiated state. Hence, in vivo experiments with recombinant laminin are required.

\section{Acknowledgements}

Not applicable.

\section{Funding}

The present study was supported by the National Research Foundation of Korea grant funded by the Korean government (grant no. NRF-2020R1A2C1009533) and Inha University Research Grant.

\section{Availability of data and materials}

The datasets used and/or analyzed during the current study are available from the corresponding author on reasonable request.

\section{Authors' contributions}

SL, DSL and JHJ conceptualized the study. SL and JHJ analyzed the data, performed the experiments and curated the data. SL, DSL and JHJ prepared and wrote the original manuscript, reviewed and edited the manuscript, including the figures. JHJ supervised the study. All authors read and approved the final manuscript.

\section{Ethics approval and consent to participate}

The human mesenchymal stem cells were isolated from tissues discarded during surgery. The study was conducted with the written informed consent of the subject who provided the tissue. The isolation of human mesenchymal stem cells from tissues was approved by the Institutional Review Board of the Catholic University of Korea, St. Mary's Hospital (approval no. KC08TISS034). All cells were provided by Dr Sung-Won Kim (St. Mary's Hospital, the Catholic University of Korea).

\section{Patient consent for publication}

Not applicable.

\section{Competing interests}

The authors declare that they have no competing interests.

\section{References}

1. Molofsky AV, Pardal R and Morrison SJ: Diverse mechanisms regulate stem cell self-renewal. Curr Opin Cell Biol 16: 700-707, 2004.

2. Rozario $\mathrm{T}$ and DeSimone DW: The extracellular matrix in development and morphogenesis: A dynamic view. Dev Biol 341: 126-140, 2010. 
3. Mahapatra C, Kim JJ, Lee JH, Jin GZ, Knowles JC and Kim HW: Differential chondro- and osteo-stimulation in three-dimensional porous scaffolds with different topological surfaces provides a design strategy for biphasic osteochondral engineering. J Tissue Eng: Jan 31, 2019 (Epub ahead of print). doi: $10.1177 / 2041731419826433$.

4. Suzuki N, Yokoyama F and Nomizu M: Functional sites in the laminin alpha chains. Connect Tissue Res 46: 142-152, 2005.

5. Miner $\mathrm{JH}$ and Yurchenco PD: Laminin functions in tissue morphogenesis. Annu Rev Cell Dev Biol 20: 255-284, 2004.

6. Patarroyo M, Tryggvason $\mathrm{K}$ and Virtanen I: Laminin isoforms in tumor invasion, angiogenesis and metastasis. Semin Cancer Biol12: 197-207, 2002.

7. Rohn F, Kordes C, Castoldi M, Götze S, Poschmann G, Stühler K, Herebian D, Benk AS, Geiger F, Zhang T, et al: Laminin-521 promotes quiescence in isolated stellate cells from rat liver. Biomaterials 180: 36-51, 2018.

8. Aumailley M, Bruckner-Tuderman L, Carter WG, Deutzmann R, Edgar D, Ekblom P, Engel J, Engvall E, Hohenester E and Jones JC: A simplified laminin nomenclature. Matrix Biol 24: 326-332, 2005

9. Klaffky E, Williams R, Yao CC, Ziober B, Kramer R and Sutherland A: Trophoblast-specific expression and function of the integrin alpha 7 subunit in the peri-implantation mouse embryo. Dev Biol 239: 161-175, 2001.

10. Miner JH, Cunningham J and Sanes JR: Roles for laminin in embryogenesis: Exencephaly, syndactyly, and placentopathy in mice lacking the laminin alpha5 chain. J Cell Biol 143: 1713-1723, 1998.

11. Navdaev A and Eble JA: Components of cell-matrix linkage as potential new markers for prostate cancer. Cancers (Basel) 3: 883-896, 2011.

12. Yu H and Talts JF: Beta1 integrin and alpha-dystroglycan binding sites are localized to different laminin-G-domain-like (LG) modules within the laminin alpha5 chain $\mathrm{G}$ domain. Biochem J 371: 289-299, 2003

13. Ido H, Harada K, Futaki S, Hayashi Y, Nishiuchi R, Natsuka Y, Li S, Wada Y, Combs AC, Ervasti JM, et al: Molecular dissection of the alpha-dystroglycan- and integrin-binding sites within the globular domain of human laminin-10. J Biol Chem 279: 10946-10954, 2004

14. Nielsen PK, Gho YS, Hoffman MP, Watanabe H, Makino M, Nomizu M and Yamada Y: Identification of a major heparin and cell binding site in the LG4 module of the laminin alpha 5 chain J Biol Chem 275: 14517-14523, 2000.

15. Blit PH, Battiston KG, Woodhouse KA and Santerre JP: Surface immobilization of elastin-like polypeptides using fluorinated surface modifying additives. J Biomed Mater Res A 96: 648-662, 2011.

16. Yeo GC and Weiss AS: Soluble matrix protein is a potent modulator of mesenchymal stem cell performance. Proc Natl Acad Sci USA 116: 2042-2051, 2019.

17. Annabi N, Mithieux SM, Boughton EA, Ruys AJ, Weiss AS and Dehghani F: Synthesis of highly porous crosslinked elastin hydrogels and their interaction with fibroblasts in vitro. Biomaterials 30: 4550-4557, 2009.

18. Meyer DE and Chilkoti A: Genetically encoded synthesis of protein-based polymers with precisely specified molecular weight and sequence by recursive directional ligation: Examples from the elastin-like polypeptide system. Biomacromolecules 3 : 357-367, 2002

19. Amruthwar SS and Janorkar AV: In vitro evaluation of elastin-like polypeptide-collagen composite scaffold for bone tissue engineering. Dent Mater 29: 211-220, 2013.

20. MacEwan SR and Chilkoti A: Elastin-like polypeptides: Biomedical applications of tunable biopolymers. Biopolymers 94 60-77, 2010.

21. Meyer DE and Chilkoti A: Purification of recombinant proteins by fusion with thermally-responsive polypeptides. Nat Biotechnol 17: $1112-1115,1999$

22. Lotfinegad P, Shamsasenjan K, Movassaghpour A, Majidi J and Baradaran B: Immunomodulatory nature and site specific affinity of mesenchymal stem cells: A hope in cell therapy. Adv Pharm Bull 4: 5-13, 2014

23. Lee DJ, Kwon J, Current L, Yoon K, Zalal R, Hu X, Xue P and Ko CC: Osteogenic potential of mesenchymal stem cells from rat mandible to regenerate critical sized calvarial defect. J Tissue Eng 10: 2041731419830427, 2019.

24. Re F, Sartore L, Moulisova V, Cantini M, Almici C, Bianchetti A, Chinello C,Dey K, Agnelli S, Manferdini C, et al:3D gelatin-chitosan hybrid hydrogels combined with human platelet lysate highly support human mesenchymal stem cell proliferation and osteogenic differentiation. J Tissue Eng 10: 2041731419845852, 2019.
25. Oswald J, Boxberger S, Jørgensen B, Feldmann S, Ehninger G, Bornhäuser $\mathrm{M}$ and Werner $\mathrm{C}$ : Mesenchymal stem cells can be differentiated into endothelial cells in vitro. Stem Cells 22: 377-384, 2004

26. Tran TC1: Kimura K, Nagano M, Yamashita T, Ohneda K, Sugimori H, Sato F, Sakakibara Y, Hamada H, Yoshikawa H, et al: Identification of human placenta-derived mesenchymal stem cells involved in re-endothelialization. J Cell Physiol 226 224-235, 2011.

27. Wen J, Zhao Z, Tong R, Huang L, Miao Y and Wu J: Prussian blue nanoparticle-labeled mesenchymal stem cells: Evaluation of cell viability, proliferation, migration, differentiation, cytoskeleton, and protein expression in vitro. Nanoscale Res Lett 13: 329, 2018

28. Kim JE, Seo HJ, Lee S and Jang JH: Evaluation of stemness maintenance properties of the recombinant human laminin $\alpha 2$ LG1-3 domains in human mesenchymal stem cells. Protein Pept Lett 26: 785-791, 2019

29. Hwang SH, Cho HK, Park SH, Lee W, Lee HJ, Lee DC, Park SH, Lim MH, Back SA, Yun BG, et al: Characteristics of human turbinate-derived mesenchymal stem cells are not affected by allergic condition of donor. PLoS One 10: e0138041, 2015.

30. Hang Pham LB, Yoo YR, Park SH, Back SA, Kim SW, Bjørge I, Mano J and Jang JH: Investigating the effect of fibulin-1 on the differentiation of human nasal inferior turbinate-derived mesenchymal stem cells into osteoblasts. J Biomed Mater Res A 105: 2291-2298, 2017

31. Livak KJ and Schmittgen TD: Analysis of relative gene expression data using real-time quantitative PCR and the 2(-Delta Delta C(T)) method. Methods 25: 402-408, 2001

32. Paiva Dos Santos B, Garbay B, Pasqua M, Chevron E, Chinoy ZS, Cullin C, Bathany K, Lecommandoux S, Amédée J, Oliveira $\mathrm{H}$, et al: Production, purification and characterization of an elastin-like polypeptide containing the Ile-Lys-Val-Ala-Val (IKVAV) peptide for tissue engineering applications. J Biotechnol 298: 35-44, 2019.

33. Tyndall A, Walker UA, Cope A, Dazzi F, De Bari C, Fibbe W, Guiducci S, Jones S, Jorgensen C, Le Blanc K, et al: Immunomodulatory properties of mesenchymal stem cells: A review based on an interdisciplinary meeting held at the Kennedy Institute of Rheumatology Division, London, UK, 31 October 2005. Arthritis Res Ther 9: 301, 2007.

34. Hynes RO: Integrins: Bidirectional, allosteric signaling machines. Cell 110: 673-687, 2002.

35. Moraes DA, Sibov TT, Pavon LF, Alvim PQ, Bonadio RS, Da Silva JR, Pic-Taylor A, Toledo OA, Marti LC, Azevedo RB, et al: A reduction in CD90 (THY-1) expression results in increased differentiation of mesenchymal stromal cells. Stem Cell Res Ther 7: 97, 2016.

36. Aslan H, Zilberman Y, Kandel L, Liebergall M, Oskouian RJ, Gazit D and Gazit Z: Osteogenic differentiation of noncultured immunoisolated bone marrow-derived $\mathrm{CD} 105^{+}$cells. Stem Cells 24: 1728-1737, 2006.

37. Sibov TT, Severino P, Marti LC, Pavon LF, Oliveira DM, Tobo PR, Campos AH, Paes AT, Amaro E Jr, F Gamarra L, et al: Mesenchymal stem cells from umbilical cord blood: Parameters for isolation, characterization and adipogenic differentiation. Cytotechnology 64: 511-521, 2012.

38. Maleki M, Ghanbarvand F, Reza Behvarz M, Ejtemaei M and Ghadirkhomi E: Comparison of mesenchymal stem cell markers in multiple human adult stem cells. Int J Stem Cells 7: 118-126, 2014.

39. Roura S, Farré J, Soler-Botija C, Llach A, Hove-Madsen L, Cairó JJ, Gòdia F, Cinca J and Bayes-Genis A: Effect of aging on the pluripotential capacity of human CD105+ mesenchymal stem cells. Eur J Heart Fail 8: 555-563, 2006

40. Yu YI, Wang W, Song L, Hu W, Dong C, Pei H, Zhou G and Yue Z: Ecto-5'-nucleotidase expression is associated with the progression of renal cell carcinoma. Oncol Lett 9: 2485-2494, 2015.

41. Colgan SP, Eltzschig HK, Eckle $\mathrm{T}$ and Thompson LF: Physiological roles for ecto-5'-nucleotidase (CD73). Purinergic Signal 2: 351-360, 2006.

42. Zimmermann H: 5'-Nucleotidase: Molecular structure and functional aspects. Biochem J 285: 345-365, 1992.

43. Lupia M, Angiolini F, Bertalot G, Freddi S, Sachsenmeier KF, Chisci E, Kutryb-Zajac B, Confalonieri S, Smolenski RT, Giovannoni R, et al: CD73 regulates stemness and epithelial-mesenchymal transition in ovarian cancer-initiating cells. Stem Cell Reports 10: 1412-1425, 2018. 